STUDI

FRANCESI

\section{Studi Francesi}

Rivista quadrimestrale fondata da Franco Simone

190 (LXIV | I) | 2020

Varia - fasc. I - gennaio-aprile 2020

\title{
MIREILLE BRÉMOND, Marguerite Yourcenar, une femme à l'Académie. Malgré eux, malgré elle...
}

\section{Serena Codena}

\section{(2) OpenEdition}

\section{Journals}

\section{Édition électronique}

URL : https://journals.openedition.org/studifrancesi/23102

DOI : $10.4000 /$ studifrancesi.23102

ISSN : 2427-5856

\section{Éditeur}

Rosenberg \& Sellier

\section{Édition imprimée}

Date de publication : 1 avril 2020

Pagination : 214-215

ISSN : 0039-2944

\section{Référence électronique}

Serena Codena, « MIREILLE BRÉMOND, Marguerite Yourcenar, une femme à l'Académie. Malgré eux, malgré elle... », Studi Francesi [En ligne], 190 (LXIV | I) | 2020, mis en ligne le 01 mai 2020, consulté le 02 août 2021. URL : http://journals.openedition.org/studifrancesi/23102 ; DOI : https://doi.org/10.4000/ studifrancesi.23102

Ce document a été généré automatiquement le 2 août 2021

\section{(c) (i) () $\Theta$}

Studi Francesi è distribuita con Licenza Creative Commons Attribuzione - Non commerciale - Non opere derivate 4.0 Internazionale. 


\title{
MIREILLE BRÉMOND, Marguerite Yourcenar, une femme à l'Académie. Malgré eux, malgré elle...
}

\author{
Serena Codena
}

\section{RÉFÉRENCE}

MIREILLE BRÉMOND, Marguerite Yourcenar, une femme à l'Académie. Malgré eux, malgré elle..., Paris, Classiques Garnier, 2019, 152 pp.

1 Le nouveau livre de Mireille Brémond se propose d'enquêter sur un événement très important non seulement pour la carrière littéraire de Marguerite Yourcenar, mais pour la société française aussi; un événement très complexe et épineux à cause de ses nombreuses contradictions et paradoxes: l'élection de la première femme à l'Académie Française. Même si les publications et les documents concernant cet épisode sont nombreux, il manquait encore un ouvrage mettant de l'ordre sur les circonstances et les enjeux de cette élection à travers un regard neutre qui ne veut être «ni partisan ni passionnel» (p. 9).

2 Le volume ne suit pas l'ordre chronologique: en effet, on commence par la consécration et la cérémonie de réception, pour passer ensuite à raconter les événements qui ont préparé cet épisode; ensuite, on analyse dans le détail les enjeux politiques et personnels de cette élection, ainsi que toutes les stratégies médiatiques mises en œuvre par les protagonistes.

3 S'il est vrai que Marguerite Yourcenar a bien mérité cette élection, il est d'autant plus vrai que cela a été instrumentalisé dans un but politique, pour suivre les nouvelles orientations de la société française et pour répondre à la cause des femmes, qui commençait déjà à marquer des points pendant ces années-là. Malgré une forte opposition de la part des membres les plus traditionnalistes et, on pourrait dire, un peu misogynes de l'Académie Française, Yourcenar pouvait compter sur l'appui de Jean 
d'Ormesson qui a largement contribué à la grande campagne médiatique autour de l'écrivaine grâce à ses contacts dans la presse, notamment dans "Le Figaro", dont il avait été le directeur pendant une certaine période.

4 De plus, l'auteure de ce volume considère aussi l'attitude contradictoire de Marguerite Yourcenar à l'égard de cet événement: d'un côté, elle a toujours montré un certain dédain pour cette institution séculaire, comme si son élection n'avait aucune importance pour elle (à ce propos, il est intéressant de voir les nombreuses critiques et les piques qu'elle adresse à l'Académie Française dans son discours de réception et dans sa correspondance); mais, de l'autre côté, ses choix et ses comportements ne semblent pas tout à fait confirmer ses discours, parce que par moments elle semble avoir œuvré pour soutenir son élection et pour forcer la main de ses adversaires. Donc, il est évident qu'il ne s'agit pas d'un simple événement mondain, mais qu'il cache des revers inattendus.

5 Mireille Brémond a su se débrouiller dans un labyrinthe de documents disparates, de lettres authentiques, de revues de presse, d'articles, très souvent contradictoires, en prenant soin de vérifier toutes les informations et de les présenter directement au lecteur pour qu'il comprenne la complexité de cette affaire.

6 Le volume est enrichi par huit annexes qui fournissent des repères utiles: la liste des émissions de radio et de télévision auxquelles Yourcenar a participé; les distinctions et les honneurs reçus; les contacts avec les académiciens, les journalistes et les membres de prix littéraires; certains documents administratifs; la liste des académiciens en charge lors de son élection; les titulaires de son fauteuil; les femmes à l'Académie et le statut de cette institution datant de 1816, sans oublier la vaste bibliographie dont l'auteure s'est servie. 